\title{
Echocardiographic guidance for MitraClip implantation
}

\author{
Michael Essandoh, MD
}

Received: 17 March 2016/ Accepted: 24 March 2016/Published online: 31 March 2016

(C) Canadian Anesthesiologists' Society 2016

Chronic moderate to severe mitral regurgitation (MR) causes left ventricular remodeling. If left untreated, MR can result in congestive heart failure and, consequently, increased morbidity and even mortality. Accordingly, patients with this condition require timely therapy. Although conventional mitral valve (MV) surgery (repair or replacement) remains the gold standard for treating MR, a significant number of patients are considered to be at too high risk for surgery and remain on pharmacotherapy alone. In an approach similar to the open Alfieri MV repair, ${ }^{1}$ a minimally invasive approach to MR treatment using the MitraClip ${ }^{\circledR}$ (Abbott Vascular, Abbott Park, IL,
USA) has recently been developed to improve systolic MV leaflet coaptation. It has been reported to produce good outcomes. ${ }^{1,2}$ The MitraClip is currently implanted using fluoroscopy and transesophageal echocardiography (TEE) for guidance., ${ }^{2,3}$

The accompanying images are from an 80-yr-old woman who presented for percutaneous MV repair of severe MR. The main pathology was a leaflet coaptation defect in the A2/P2 and A3/P3 regions of the MV. Using fluoroscopy and two- and three-dimensional TEE guidance, a single Mitraclip was placed in the A2/P2 region. Her severe MR was reduced to mild MR.

M. Essandoh, MD ( $\square)$

Division of Cardiothoracic and Vascular Anesthesiology,

Department of Anesthesiology, The Ohio State University,

Wexner Medical Center, Columbus, OH, USA

e-mail: michael.essandoh@osumc.edu 

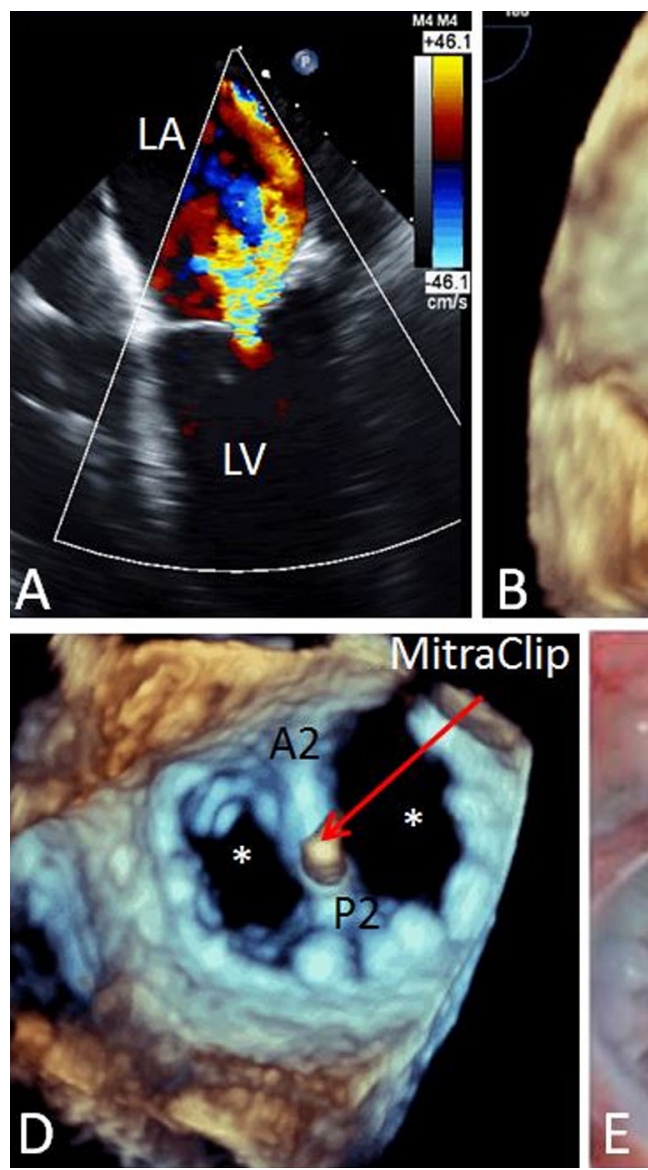

Figure In panel A, a two-dimensional (2D) transesophageal echocardiographic (TEE) mid-esophageal four-chamber view with colour Doppler shows the presence of severe mitral regurgitation (MR) prior to MitraClip implantation. A corresponding threedimensional (3D) TEE en face view in panel $\mathrm{B}$ can be seen from the left atrial (LA) perspective, showing the mitral valve (MV) in diastole. A coaptation defect is seen at the level of the A2/P2 segments extending toward the A3/P3 segments. Panel C shows a preimplantation image of a MitraClip ${ }^{\circledR}$ (Abbott Vascular, Abbott Park, IL, USA). A 3D TEE en face view (LA trial perspective) of the MV in

\section{Competing interest None declared.}

Editorial responsibility This submission was handled by Dr. Hilary P. Grocott, Editor-in-Chief, Canadian Journal of Anesthesia.

\section{References}

1. Alfieri $O$, Maisano $F$. An effective technique to correct anterior mitral leaflet prolapse. J Card Surg 1999; 14: 468-70. diastole is seen in panel D after repair with the MitraClip. This image demonstrates MitraClip implantation at the A2/P2 region, which creates a double-orifice MV (asterisk), similar to an Alfieri repair. ${ }^{1}$ This image is notably similar to that seen in panel E, which is an anatomic specimen from a porcine MV that shows an endothelialized Mitraclip six months after MV repair. As seen in panel F, the 2D TEE mid-esophageal four-chamber view with colour flow Doppler shows only mild residual MR after MV repair with the MitraClip. Panels C and $\mathrm{E}$ were reproduced, with permission, from Abbott Vascular, Abbott Park, IL, USA

2. Feldman T, Foster E, Glower DD, et al. Percutaneous repair or surgery for mitral regurgitation. N Engl J Med 2011; 364: 1395406.

3. Whitlow PL, Feldman T, Pedersen WR, et al. Acute and 12-month results with catheter-based mitral valve leaflet repair: the EVEREST II (Endovascular Valve Edge-to-Edge Repair) High Risk Study. J Am Coll Cardiol 2012; 59: 130-9. 